\title{
Estratégia para acurácia de mapas de cobertura da terra no semiárido brasileiro: Estudo de caso no município de Martins/RN.
}

\author{
Strategie for mapping land cover maps in the Brazilian semi-arid region: Case study in the \\ municipality of Martins / RN. \\ GUEDES $^{1}$, J. C. F; CESTARO ${ }^{2}$, L. A. \\ Janiocf.guedes@gmail.com
}

\begin{abstract}
Resumo
Estudos relacionados ao desenvolvimento sustentável e ao planejamento adequado dos recursos naturais são um dos desafios da sociedade atual, caracterizando padrões ambientais como, por exemplo, o levantamento da cobertura da terra. Com o advento das geotecnologias, estudos acerca da cobertura da terra, possibilitam gerar mapas distinguindo diferentes tipos de cobertura da terra. Por sua vez, a exatidão de um mapa é uma etapa primordial no final de qualquer classificação. A avaliação da acurácia de mapas, por sua vez, permite verificar erros oriundos da classificação. Pretende-se com este trabalho aplicar estratégias para verificar a acurácia de mapas de cobertura da terra. Para tanto, utilizou-se de um mapa de uso e cobertura da terra do município de Martins/RN, realizado pelo INPE em 2011, e o software ArcGis 10.2. Em campo foram observados e coletados às coordenadas de 125 pontos de controle, e posteriormente elaborado uma matriz de confusão e aplicados o índice de Exatidão Global e o índice Kappa. Em suma, a classificação do INPE obteve um índice de Exatidão Global de 55,20\%, e um índice Kappa de 43,21\%, enquadrando-se como "Boa" segundo Landis \& Kock (1977).
\end{abstract}

Palavras chave: Sensoriamento Remoto. Validação de mapeamentos. Cobertura da terra.

\begin{abstract}
Studies related to sustainable development and proper planning of natural resources are one of the challenges of today's society, characterizing environmental standards such as surveying land cover. With the advent of geotechnologies, studies on land cover allow the generation of maps distinguishing different types of land cover. On the other hand, the accuracy of a map is a primordial step at the end of any classification. The evaluation of the accuracy of maps, in turn, allows to verify errors from the classification. This work intends to apply strategies to verify the accuracy of land cover maps. For this purpose, a land use and land cover map of the municipality of Martins / RN, carried out by INPE in 2011, and ArcGis 10.2 software was used. In the field were observed and collected at the coordinates of 125 control points, and later a confusion matrix was developed and the Global Accuracy index and the Kappa index were applied. In sum, the INPE classification obtained a Global Accuracy Index of $55.20 \%$, and a Kappa Index of $43.21 \%$, which was classified as "Good" according to Landis \& Kock (1977).
\end{abstract}

Keywords: Remote Sensing. Validation of mappings. Land cover.

\section{INTRODUÇÃO}

Cerca de $40 \%$ do globo terrestre está ocupado pelas florestas tropicais e subtropicais, entre as quais $42 \%$ são compreendidas pelas florestas secas, onde inclui-se a maior formação vegetal do Nordeste brasileiro, à Caatinga, bioma exclusivamente brasileiro ocupando uma área de $11 \%$ do território nacional, ocupando o que seria mais de $70 \%$ do território do Nordeste (ANDRADELIMA, 1981; SAMPAIO, 1995). 
Composta predominantemente por plantas de porte arbustivo arbóreo, caducifólias e muito tolerantes ao déficit hídrico, em grande parte determinada pelo clima, relevo e embasamento geológico que, em suas múltiplas inter-relações, resultam em sistemas ecológicos bastante variados (ANDRADE-LIMA, op cit., SAMPAIO, op cit.,). Em outras palavras, as Caatingas (PRADO, 2003) podem ser caracterizadas como florestas arbóreas ou arbustivas, compreendendo principalmente árvores e arbustos de porte baixo muitos dos quais apresentam espinhos, microfilia e algumas características xerofíticas. Embora os esforços para o conhecimento da vegetação, estado de degradação e localização de áreas prioritárias para conservação, estudos de como a biodiversidade se distribui neste bioma ainda são escassos (VELOSO, 2002).

Consequentemente, diferentes sistemas de classificação da vegetação têm sido desenvolvidos para a grande variedade de escalas de análise e seus propósitos.

Jacomini et al (1971) explica que a interferência do homem provocou grande modificação na fitofisionomia do Estado do Rio Grande do Norte.

Por sua vez, a exatidão de um mapa é uma etapa primordial no final de qualquer classificação. Neste contexto, a avaliação da acurácia e precisão de mapas permitem verificar erros oriundos do processo de atribuição dos pixels a determinadas classes geradas a partir da classificação utilizada e consequentemente avaliar o nível de confiabilidade das informações contidas nos mesmos (CONGALTON, 1991). Essa avaliação pode ser obtida a partir de "matrizes de classificação" (PONZONI \& SHIMABUKURO, 2010) ou "matriz de confusão" (CONGALTON, 1991). Onde aplicando índices como o índice de Exatidão Global e o índice KAPPA (FOODY, 2002; PONZONI \& ALMEIDA, 1996) é possível estimar a exatidão de um mapa temático.

Localizado no oeste do Estado, o município de Martins de acordo com os trabalhos realizados a nível exploratório a cerca da vegetação, caracteriza-se por apresentar uma vegetação do tipo Caatinga hiperxerófila, ou seja, é a Caatinga que apresenta xerofitismo ${ }^{1}$ mais acentuado, característica da zona de clima semiárido do Nordeste (JACOMINI et al., 1971). Subdividida em Caatinga do tipo: Arbórea densa, vegetação arbórea constituída por árvores com altura em torno de 8 a 10 metros de altura. Como também a Caatinga do tipo: Arbórea aberta, composta por árvores e arbustos de alturas variáveis, esparsamente distribuídas sobre um estrato herbáceo estacional (SALGADO et al, 1981).

\footnotetext{
${ }^{1}$ Plantas que podem suportar a escassez de água.
} 
Como também Floresta Subcaducifólia na parte serrana do município, caracterizando-se por apresentar caráter semi-decíduo ${ }^{2}$ e encontra-se atualmente devastada em sua quase totalidade, cedendo lugar as formações secundarias (capoeiras), culturas e pastagens (JACOMINI et al., 1971).

Em uma escala de semidetalhe, pouco se conhece sobre a variação da vegetação em diferentes tipos fisionômicos da Caatinga no Município.

Um mapa de uso e ocupação do solo em escala de semidetalhe realizado pelo Instituto Nacional de Pesquisas Espaciais - INPE, em 2011, identificou 6 (seis) classes, sendo elas; Caatinga preservada, Caatinga Degradada, Lavoura, Solo exposto, corpos d'água e Zona Urbana.

Dessa forma, frente a essa escassez de dados referentes aos estudos para se avaliar a veracidade dos mapeamentos de cobertura da terra obtidos por classificação de imagens de sensoriamento remoto pretende-se com este trabalho aplicar estratégias para verificar a acurácia de mapas de cobertura da terra no semiárido brasileiro.

\section{METODOLOGIA}

O município de Martins abrange uma área de $169 \mathrm{~km}^{2}$ e localiza-se a Oeste no Estado do Rio Grande do Norte na mesorregião Oeste Potiguar e microrregião de Umarizal, distando aproximadamente $380 \mathrm{~km}$ de Natal, capital do Estado (ver figura 01). A população total residente é de 8.218 habitantes apresentando uma densidade demográfica de 48,49 hab $/ \mathrm{km}^{2}$ e um Índice de Desenvolvimento Urbano (IDH) igual a 0,622. (IBGE, s.d) ${ }^{3}$

\footnotetext{
${ }^{2}$ Parte dos componentes perdem as folhas durante o período seco.

${ }^{3}$ Perfil do Município de Martins/RN. Disponível em:

<http://www.cidades.ibge.gov.br/xtras/perfil.php?lang=\&codmun=240740>: Acesso em 02 de maio de 2015.
} 


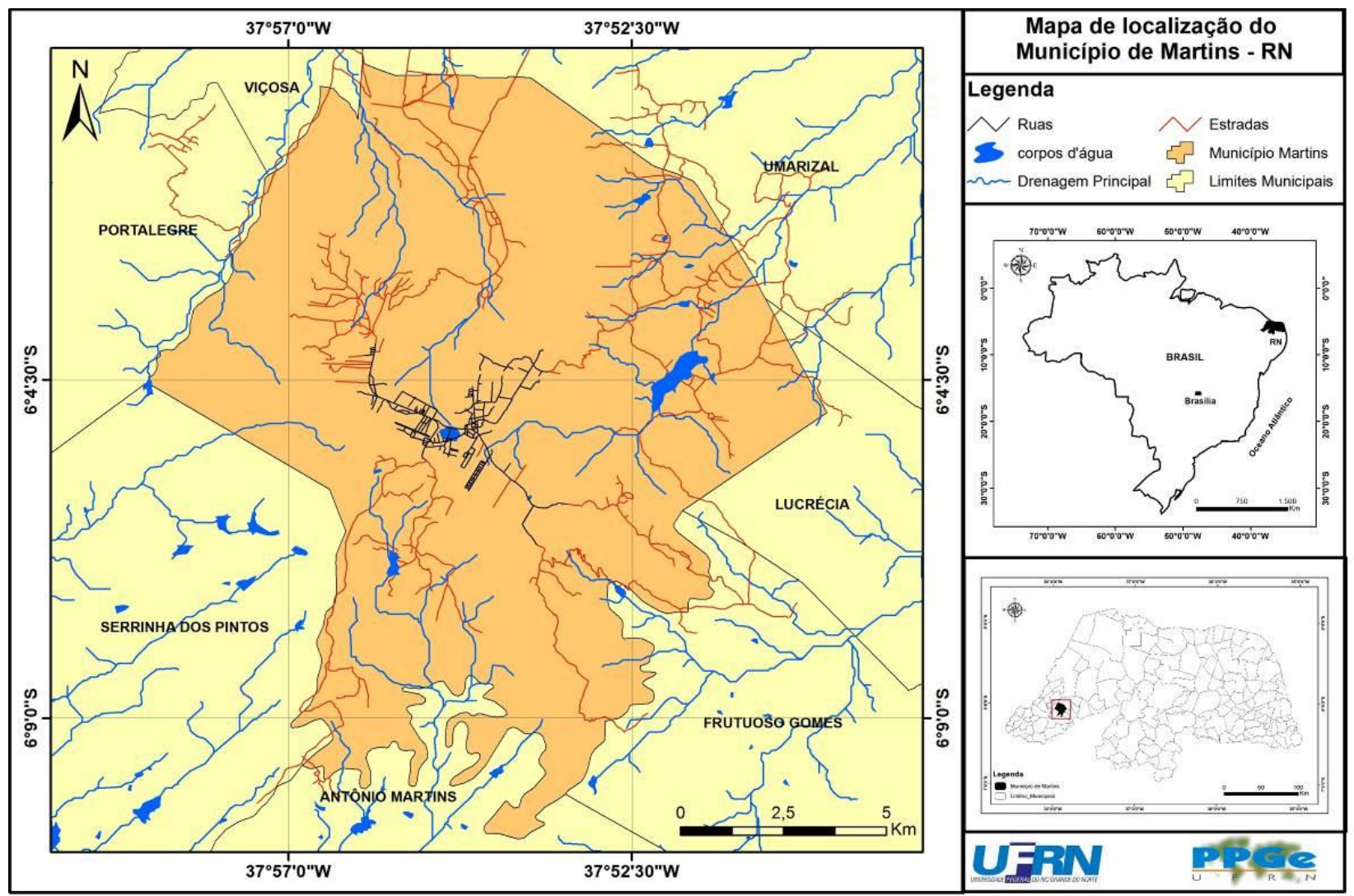

Figura 01: Mapa de localização do Município de Martins - RN. Fonte dos dados: Malha digital em formato shapefile. Disponível em <http://downloads.ibge.gov.br/downloads_geociencias.htm>. Acesso em 02 de maio de 2015.

Quanto aos aspectos geológicos, de acordo com a CPRM (2005), o município de Martins está inserido geologicamente na Província Borborema e Serra dos Martins, basicamente caracterizados por duas unidades litoestratigráficas, o embasamento cristalino do período Précambriano, formado por gnaisses, xistos e anfibólitos, e a Formação sedimentar Serra do Martins, de idade Terciária Inferior, formada por arenitos caulínicos, conglomerados e siltitos.

O município apresenta uma cota altimétrica que varia de 210 a 720 metros aproximadamente, apresentando como unidades de relevo a Depressão Sertaneja (terrenos baixos situados na Chapada do Apodi), sedimentos que afloram em chapadas de relevo plano a levemente ondulado, constituídos por arenitos médios a conglomeráticos, argilosos (por vezes cauliníticos) e crosta laterítica com seixos de quartzo (CPRM, 2005) (ver figura 02). 


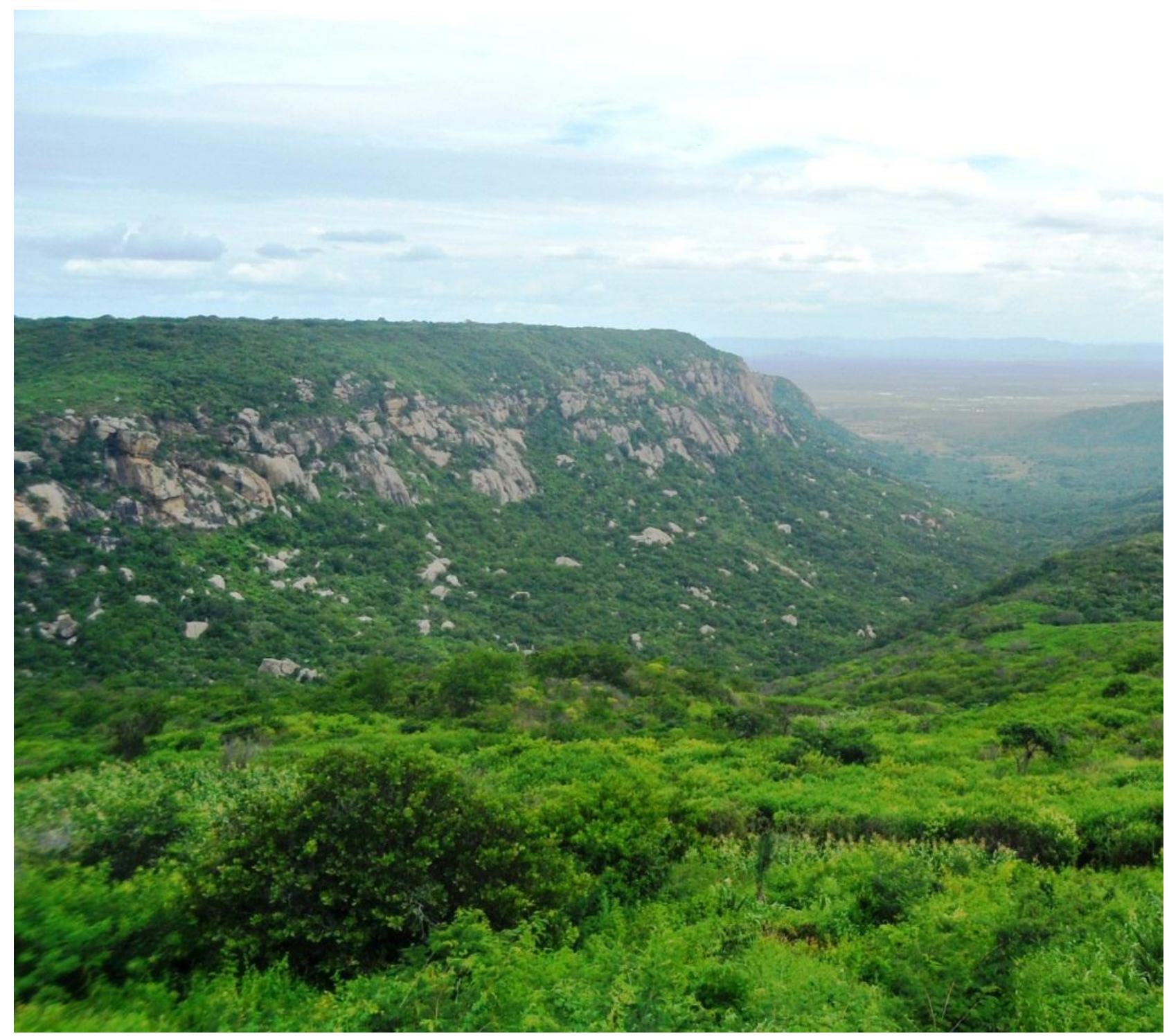

Figura 02: Platô (Formação Serra de Martins) localizada no Município de Martins - RN. Fonte: Acervo do autor.

O clima da região de acordo com a classificação de Köppen (ALVARES et al., 2013) é "As", clima tropical com chuvas no inverno. Embora a área de estudo esteja situada dentro do bioma Caatinga, a altitude exerce considerável influência na distribuição das chuvas e nas temperaturas, de parte do município (a serra) apresentando características peculiares, como, clima subúmido, precipitação média anual entre 900 e 1300 mm (quase 300 mm superior ao seu entorno), tendo como característica, um "inverno" seco e um "verão" que concentra a precipitação anual, com estação seca em média de 6 meses (Julho-Dezembro) (AB'SABER, 1999; REIS, 1976) (ver figura 03). 


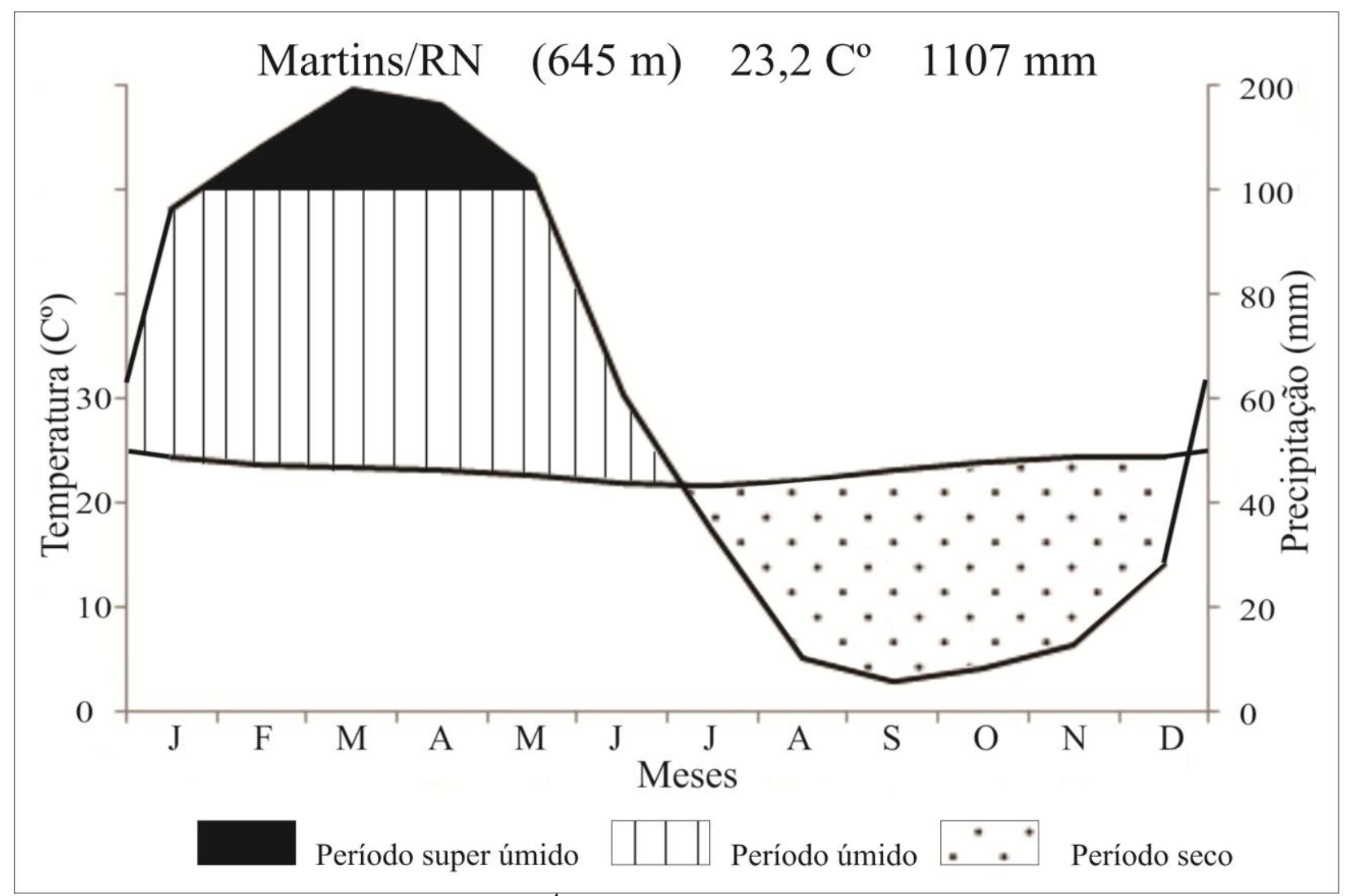

Figura 03: Diagrama Climático de Walter ${ }^{4}$ para a sede do município de Martins - RN. Fonte: Elaborado pelo autor a partir de dados de temperatura média mensal e precipitação acumulada mensal 1911-1990, disponíveis em < http://www.dca.ufcg.edu.br/clima/dadosrn.htm >

Sobre os aspectos hidrográficos, o município encontra-se inserido na Bacia Hidrográfica do Rio Apodi-Mossoró, os principais rios são: o Rio Trapiá, Riachos dos Picos e Quixeré, e como principais açudes: o Alívio, do Chapéu e o Nogueira (CPRM, 2005) (ver figura 04).

\footnotetext{
${ }^{4}$ WALTER, H. Vegetação e Zonas Climáticas: Tratado de Ecologia Global. Tradução de Anna Terzi Giova, Hildegard T. Buckup. São Paulo: EPU, 1986.
} 


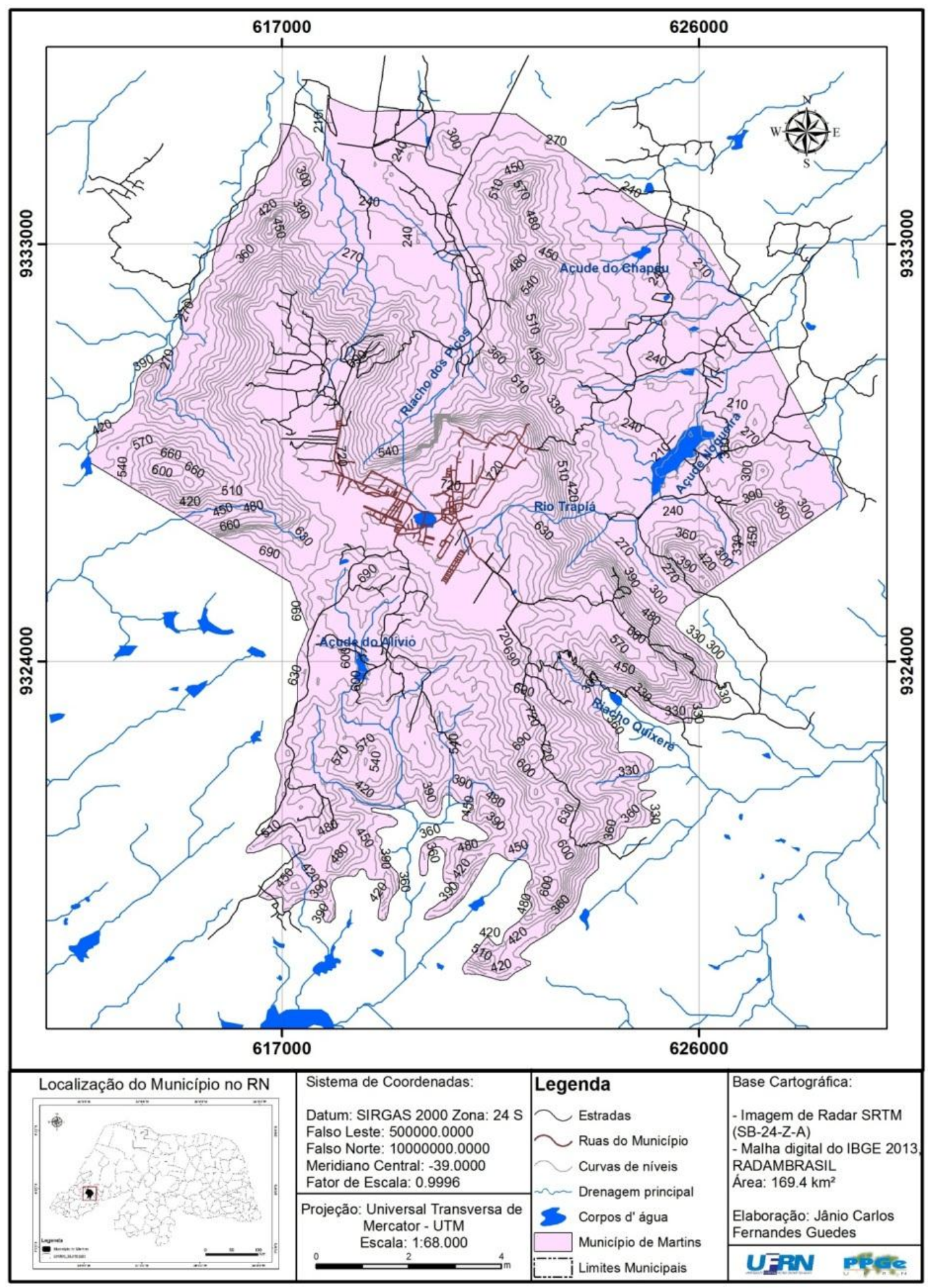

Figura 04: Mapa hidrográfico e hipsométrico do município de Martins - RN. Fonte: Elaborado pelo autor, a partir de dados em formato digital de shapefile do IBGE (2013) e uma imagem de radar SRTM (SB24-Z-A) ${ }^{5}$.

\footnotetext{
${ }^{5}$ Disponível em <http://www.sat.cnpm.embrapa.br>. Acesso em 12 de janeiro de 2016.
} 
Os tipos de solo encontrados em Martins são: os Argissolos, Latossolo Vermelho e Amarelo, Luvissolo e Neossolo Regolítico (JACOMINI, 1971; IBGE, 2015).

Quanto à vegetação, o município apresenta uma vegetação do tipo "Caatinga hiperxerófila" (é a Caatinga que apresenta xerofitismo mais acentuado, característica da zona de clima semiárido do Nordeste), em quase todo o município, com predominância de plantas espinhosas deciduais e plantas de porte mais baixo e espalhadas, destacando-se a: jurema-preta, mufumbo, faveleiro, marmeleiro, xique-xique e facheiro (JACOMINI, 1971; IBGE, 2012). Em sua porção mais central (no platô da Serra de Martins), apresenta uma vegetação de do tipo Floresta subcaducifólia e encontra-se atualmente devastada em sua quase totalidade, cedendo lugar as formações secundárias (capoeiras), culturas e pastagens, como espécies mais encontradas podem ser citadas: pau d'arco amarelo, pau-ferro, pau-santo, jatobá, marmeleiro, sucupira-mirim, catanduba e pau-d'óleo, além espécies de nome vulgar, localmente chamados de: codoie, inharé, cipauba, calumbi e outras (JACOMINI, 1971).

Utilizou-se de um mapa de uso e cobertura da terra realizado pelo INPE $^{6}$ em 2011, elaborado a partir de uma imagem do sensor CCD (High Resolution CCD Camera ou Câmera Imageadora de Alta Resolução) do Satélite CBERS 2B de Julho de 2008, identificando as seguintes classes: Caatinga Preservada, Caatinga Degradada, Solo Exposto, Lavoura, Corpos d'água e Urbano. A mesma foi projetada para o Sistema SIRGAS 2000 e georreferenciado na grade de coordenadas UTM (Universal Transversa de Mercator).

Para avaliar a acurácia do mapa de uso e cobertura da terra realizado pelo INPE (2011), foram tomadas como verdade as classes de cobertura da terra obtidas em 125 pontos amostrais observados em campo distribuidos pelo município.

Levando em consideração a resolução espacial das imagens utilizadas na pesquisa do INPE (20 metros), o critério para obtenção dos pontos em campo levou em consideração áreas aproximadamente homegênias de fácil localização na imagem.

As coordenadas dos pontos em campo foram obtidas com o auxílio de um GPS de navegação da marca Garmin, onde foram observadas as classes de cobertura da terra. Para as formações vegetais naturais obtiveram-se a regularidade da estrutura quanto ao porte, altura média e estratificação da vegetação.

As classes de vegetação natural foram denominadas seguindo o Sistema de Classificação da Vegetação Brasileira proposto pelo IBGE (2012) e as classes de cobertura com influência humana mais intensa, seguindo o Manual de Uso da Terra do IBGE (2006).

\footnotetext{
${ }^{6}$ Disponível em <http://www.geopro.crn2.inpe.br/martins_rn.htm> Acesso em 10 de outubro de 2014.
} 
A partir das coordenadas de cada ponto observado em campo, os mesmos foram distribuidos no mapa, para confrontar as classes de cobertura da terra observadas em campo com as classes da imagem classificada.

Dessa forma, foi construída uma matriz de confusão para avaliar o mapeamento do mapa do INPE.

A matriz de confusão é formada por um arranjo quadrado de números dispostos em linhas e colunas que expressam o número de unidades amostradas de uma classe particular inferida por um classificador (ou regra de decisão), comparado com a classe real verificada no campo (CONGALTON, 1991; PONZONI \& SHIMABUKURO, 2010) (ver tabela 01).

Tabela 01: Representação matemática de uma matriz de confusão. Fonte: Adaptado de Congalton (1991).

\begin{tabular}{c|c|c|c|c}
\hline \multirow{2}{*}{$\begin{array}{c}\text { Dados } \\
\text { classificados }\end{array}$} & \multicolumn{4}{|c}{ Dados obtidos em campo } \\
\cline { 2 - 5 } & Classe 01 & Classe 02 & Classe 03 & Total \\
\hline Classe 01 & P11 & P 12 & P 13 & SL1 $=\sum(11 \ldots 13)$ \\
\hline Classe 02 & P 21 & P 22 & P 23 & SL2 $=\sum(21 \ldots 23)$ \\
\hline Classe 03 & P 31 & P 32 & P 33 & SL3 $=\sum(31 \ldots 33)$ \\
\hline \multirow{2}{*}{ Total } & SC1 & SC2 & SC3 & SPL $=\sum$ (SL1...SL3) \\
& $\sum(11 \ldots 13)$ & $\sum(21 \ldots 32)$ & $\sum(13 \ldots 33)$ & SPC $=\sum$ (SC1...SC3) \\
\hline
\end{tabular}

Soma da diagonal principal - SDP
SDP $=\sum(11 \ldots 33)$

Onde: $\mathrm{P}$ - Pontos de análise;

SL - Soma das linhas;

$\mathrm{SC}$ - Soma das colunas;

SDP - Soma dos pontos da diagonal principal classificados corretamente;

SPL - Soma total dos pontos na linha principal;

SPC - Soma total dos pontos na coluna principal;

Obs: Os valores referentes a SPL e SPC são iguais uma vez que correspondem ao número de pontos observados em campo.

A partir das matrizes foi avaliada a acurácia das classificações dos mapas de cobertura da terra a partir do índice de Exatidão Global e do índice de Kappa.

A exatidão global é calculada dividindo a soma da diagonal principal da matriz de confusão, pelo número total de amostras coletadas, conforme a equação 01:

\section{$P_{0}=$ Erro $!$ Fonte de referência não encontrada.}


Onde: $\boldsymbol{P o}=$ Coeficiente de Exatidão Global;

nii = Elementos da diagonal principal da Matriz de Confusão;

$N$ = Número total de pontos da Matriz de confusão;

Para cada uma das classes de cobertura da terra identificada, aplicou-se o índice de Exatidão Global para ober a acurácia das classes individualmente (acurácia do produtor e do usuário) para ambos os índices de vegetação utilizados na pesquisa, classificando os erros de omissão (pontos de uma classe específica que foram classificadas como outras) e comissão (pontos de outras classes classificadas como uma classe específica). Posteriormente, aplicou-se o mesmo índice para toda a matriz para avaliar a acurácia do mapeamento.

Em seguida, aplicou-se o índice Kappa, onde obteve a acurácia total da classificação, uma vez que este índice envolve toda a matriz de confusão, diferentemente do índice de Exatidão Global que considera apenas os pontos classificados corretamente. Tal equação é expressa da seguinte forma.

$\mathbf{K}=$ (N Erro! Fonte de referência não encontrada./ ( $\boldsymbol{n}^{2}$ - Erro! Fonte de referência não encontrada.)

Onde: $\boldsymbol{K}$ - é uma estimativa do coeficiente Kappa;

$\boldsymbol{X}_{i i}$ - é o valor na linha $i$ e coluna $i$;

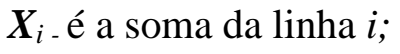

$\boldsymbol{X}+\boldsymbol{i}$ - é a soma da coluna $i$ da matriz de confusão;

$\boldsymbol{n}$ - é o número total de pontos e $c$ o número total de classes;

A qualidade da classificação para ambos os mapas foram avaliadas a partir da tabela de avaliação da qualidade da classificação proposta por Landis \& Kock (1977). (ver tabela 02)

Tabela 02: Qualidade da classificação segundo intervalos do coeficiente de concordância Kappa. Fonte: Landis \& Koch (1977).

\begin{tabular}{c|c}
\hline Índice de Kappa & Grau de concordância \\
\hline$<0,00$ & Péssimo \\
$0,00-0,20$ & Ruim \\
$0,21-0,40$ & Razoável \\
$0,41-0,60$ & Bom \\
$0,61-0,80$ & Muito Bom \\
\hline
\end{tabular}




$$
0,81-1,00
$$

Excelente

\section{RESULTADOS E DISCUSSÃO}

Inicialmente, foram observadas em campo oito classes de cobertura da terra no município de Mantins/RN no período de setembro de 2015. Sendo elas: Floresta estacional, Savana-Estépica florestada, Savana-Estépica arborizada, Agricultura permanente e Temporária, Solo exposto, Área urbana e Corpo d'água apresentados na figura 05.
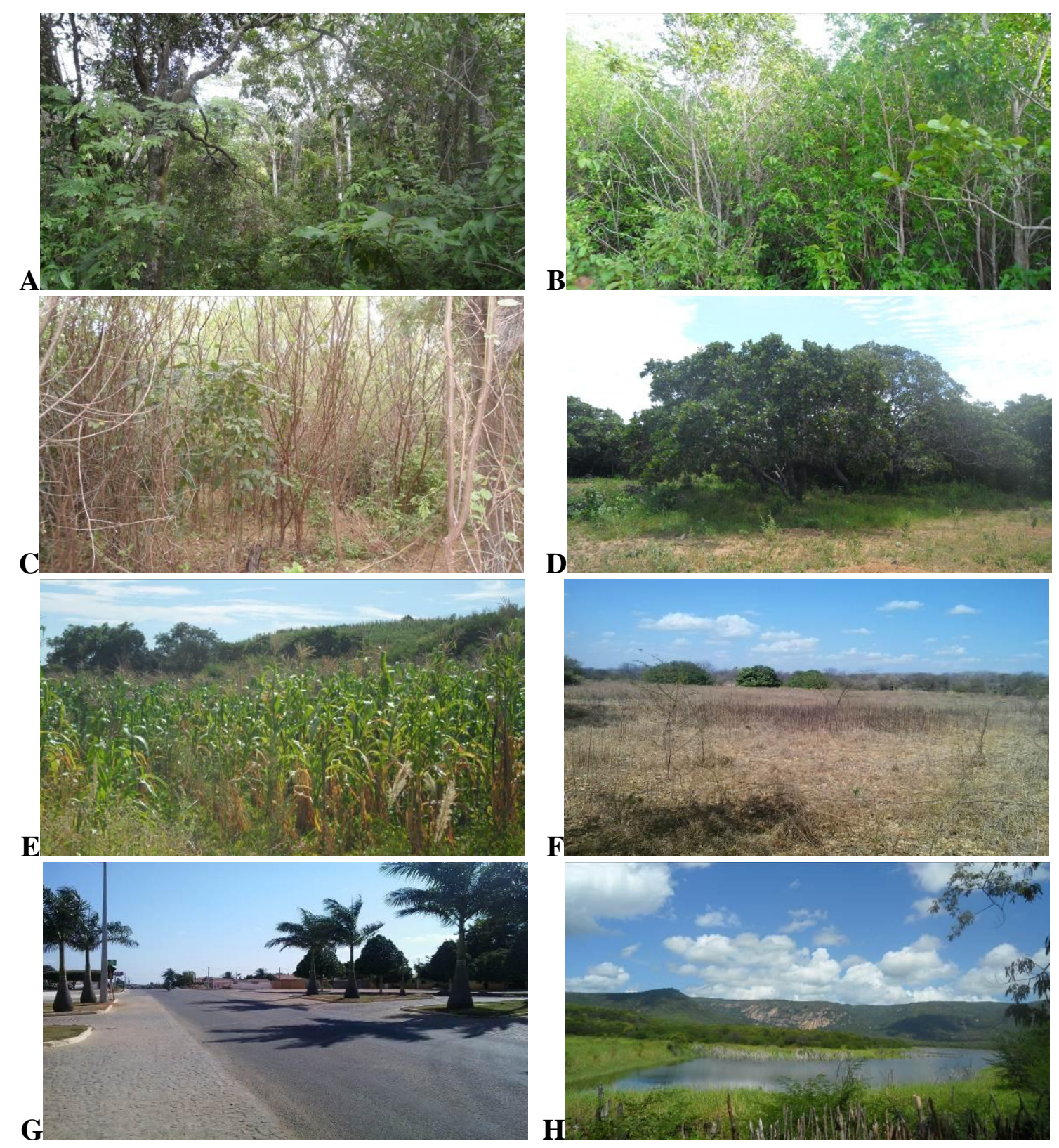
Figura 05: Classes de cobertura da terra identificadas no município de Martins - RN: A) Floresta estacional; B) Savana-Estépica florestada; C) Savana-estépica arborizada; D) Agricultura permanente; E) Agricultura temporária; F) Solo exposto; G) Área urbana. H) Corpos d'água Fonte: Acervo do autor:

As classes de cobertura da terra estão descritas no manual técnico da vegetação brasileira do IBGE (2012) da seguinte forma: -Floresta estacional: caracterizada for conter uma vegetação mais ou menos densa, em sua maioria, apresentam alturas entre 2-7 metros, e não muito raro ultrapassando os 10 metros de altura; -Savana-Estépica Florestada: Caracterizado por plantas que variam em sua maioria de 2-7 metros de altura, periodicamente decíduas, mais ou menos adensadas por grossos troncos em geral, amplamente esgalhados e espinhosos; -Savana-Estépica Arborizada: Composta por uma vegetação denominado de arbustivo-arbóreo de características semelhantes a da Savana-Estépica Florestada, com vegetação entre 2-7 metros de altura, sendo menos densa que a Savana-Estépica florestada; Agricultura permanente; caracterizado principalmente com cajueiros Agricultura temporária; caracterizado, em sua maioria, com culturas de feijão e milho; Solo exposto - Referente a áreas com pouca ou nenhuma vegetação revestindo o solo; -Área urbana - Áreas com construções de casas entre outras edificações; -Corpos d'água - Referente aos açudes do município.

A partir de campanhas de campo realizadas no período de setembro de 2015 , foram obtidos 125 pontos de controle com a classe de cobertura da terra identificada localmente e suas coordenadas georáficas no Datum SIRGAS 2000, o mesmo utilizado para georreferenciar as imagens utilizadas nos mapeamentos. A distribuição dos pontos de controle no município está representado na Figura 06 e a frequência das classes de cobertura amostrais está na Tabela 03.

Tabela 03: Distribuição de frequência dos pontos de controle obtidos em campo segundo as classes de cobertura da terra no município de Martins - RN. Fonte: Elaborado pelo autor.

\begin{tabular}{c|c}
\hline CLASSES DE COBERTURA DA TERRA & No DE PONTOS OBSERVADOS $^{\mathbf{0}}$ DE \\
\hline Floresta estacional & 22 \\
Savana-Estépica florestada & 37 \\
Savana-Estépica arborizada & 10 \\
Agricultura permanente & 20 \\
Agricultura temporária & 14 \\
Solo exposto & 13 \\
Área urbana & 7 \\
Corpos d’água & $\mathbf{1 2 5}$ \\
\hline TOTAL &
\end{tabular}




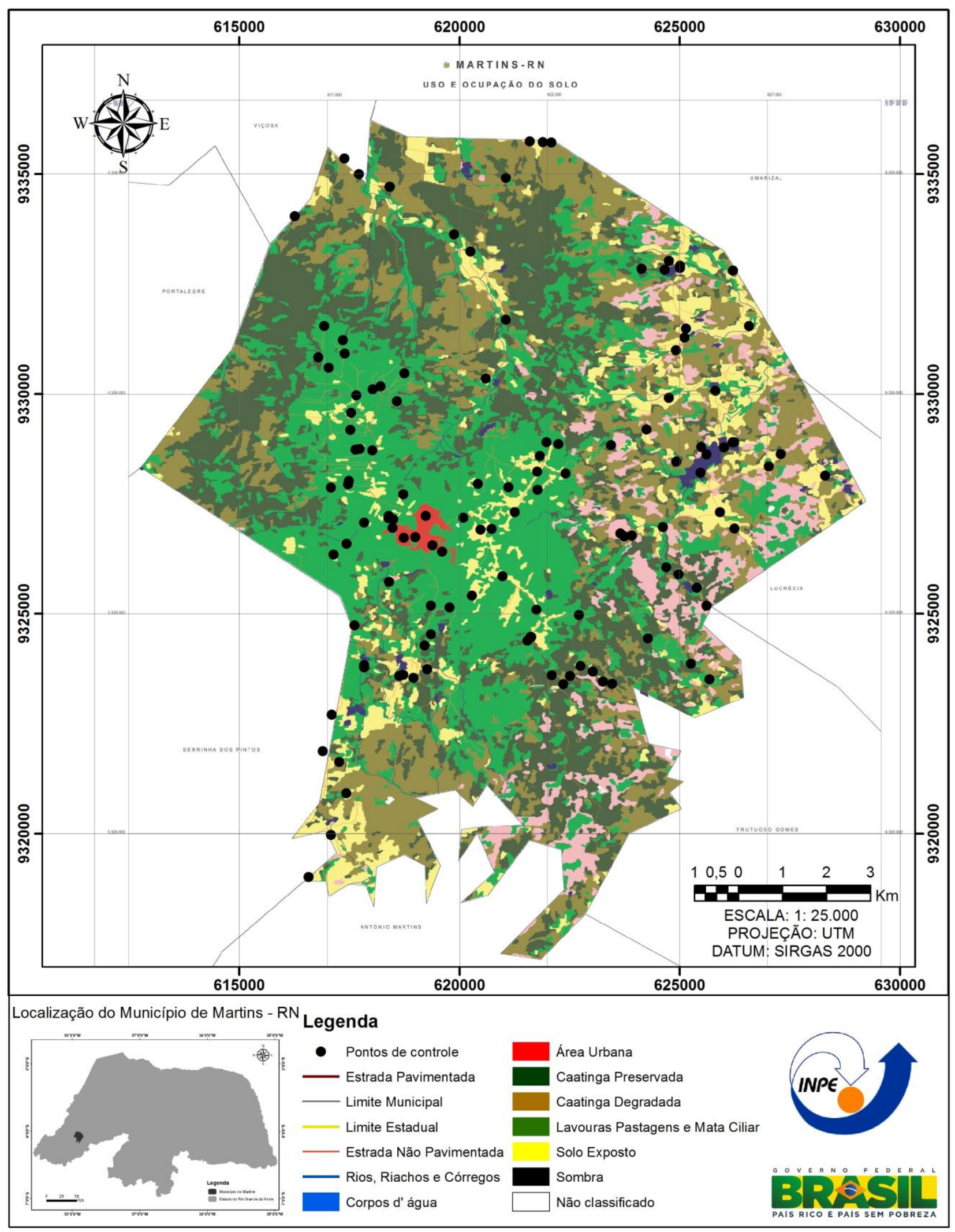


Figura 06: Mapa de uso e cobertura da terra com a distribuição dos pontos de controle obtidos em campo no municipío de Martins - RN. Fonte: Adaptado a partir de um mapa de uso e cobertura da terra do INPE. Disponível em: <http://www.geopro.crn2.inpe.br/martins_rn.htm> Acesso em 10 de outubro de 2014.

\subsection{ACURÁCIA DO MAPEAMENTO DO INPE.}

Diante dos pontos observados em campo, os mesmos foram distribuidos no mapa de cobertura da terra elaborado pelo INPE e gerado uma Matriz de confusão, obtendo-se o índice Exatidão Global, acurácia do produtor e do usuário e o índice Kappa (FIG 07 e TAB 04).

\begin{tabular}{c|c|c|c|c|c|c|c}
\hline $\begin{array}{c}\text { CLASSES DE } \\
\text { COBERTUA DA } \\
\text { TERRA }\end{array}$ & $\begin{array}{c}\text { Caatinga } \\
\text { preservada }\end{array}$ & $\begin{array}{c}\text { Caatinga } \\
\text { degradada }\end{array}$ & Lavoura & Urbano & $\begin{array}{c}\text { Solo } \\
\text { exposto }\end{array}$ & $\begin{array}{c}\text { Corpos } \\
\text { d' água }\end{array}$ & Total \\
\hline Caatinga preservada & $\mathbf{5}$ & 7 & 0 & 0 & 0 & 0 & 12 \\
\hline Caatinga degradada & 8 & $\mathbf{2 0}$ & 0 & 0 & 3 & 0 & 31 \\
\hline Lavoura & 9 & 7 & $\mathbf{2 6}$ & 0 & 5 & 0 & 47 \\
\hline Urbano & 0 & 0 & 1 & $\mathbf{5}$ & 0 & 0 & 6 \\
\hline Solo exposto & 1 & 4 & 3 & 8 & $\mathbf{6}$ & 0 & 22 \\
\hline Corpos d' água & 0 & 0 & 0 & 0 & 0 & $\mathbf{7}$ & 7 \\
\hline Total & 23 & 38 & 30 & 13 & 14 & 7 & \\
\hline \multicolumn{7}{|c|}{ Noma da diagonal principal =69 } \\
\hline
\end{tabular}

Tabela 04: Matriz de confusão para dados do mapa de cobertura da terra elaborado pelo INPE. Fonte: Elaborado pelo autor.

Como o INPE utiliza em sua classificação seis classes de cobertura da terra, algumas classes tiveram que ser agrupadas conforme as observações realizadas em campo (TAB 05).

\begin{tabular}{c|c}
\hline $\begin{array}{c}\text { CLASSES DE COBERTURA DA TERRA } \\
\text { IDENTIFICADAS EM CAMPO }\end{array}$ & $\begin{array}{c}\text { CLASSES DE COBERTURA DA } \\
\text { TERRA (MAPA DO INPE) }\end{array}$ \\
\hline Floresta estacional & Caatinga preservada \\
\hline Savana-Estépica florestada & Caatinga degradada \\
\hline Savana-Estépica arborizada & Lavoura \\
\hline Agricultura permanente & Solo exposto \\
\hline Agricultura temporária & Urbano \\
\hline Solo exposto & Corpos d'água \\
\hline Área urbana & Corpos d'água
\end{tabular}

Tabela 05: Classes de cobertura da terra (INPE). Fonte: Elaborado pelo autor 
Na matriz de confusão verificou-se o nível da acurácia do produtor e do usuário, obtendo assim os erros de omissão e comissão para ambas as classes de cobertura da terra estabelecidas, bem como o valor do índice de Exatidão Global para toda a classificação, finalizando com a obtensão do índice Kappa (TAB 06 e 07).

\begin{tabular}{c|c|c}
\hline CLASSES DE COBERTURA DA TERRA & $\begin{array}{c}\text { Veracidade } \\
\text { dos dados }(\boldsymbol{\%})\end{array}$ & $\begin{array}{c}\text { Erros de } \\
\text { comissão (\%) }\end{array}$ \\
\hline Caatinga preservada & 21,7 & 78,3 \\
Caatinga degradada & 52,6 & 47,4 \\
Lavoura & 86,7 & 13,3 \\
Urbano & 38,5 & 61,5 \\
Solo exposto & 42,9 & 57,1 \\
Corpos d' água & 100,0 & 0 \\
\hline Exatidão global (Produtor) & $\mathbf{5 7 , 0 6}$ & $\mathbf{4 2 , 9 4}$ \\
\hline
\end{tabular}

Tabela 06: Classificação do Produtor para o mapeamento do INPE. Fonte: Elaborado pelo autor.

\begin{tabular}{c|c|c}
\hline CLASSES DE COBERTURA DA TERRA & $\begin{array}{c}\text { Veracidade } \\
\text { dos dados }(\boldsymbol{\%})\end{array}$ & $\begin{array}{c}\text { Erros de } \\
\text { omissão (\%) }\end{array}$ \\
\hline Caatinga preservada & 41,7 & 58,3 \\
Caatinga degradada & 64,5 & 35,5 \\
Lavoura & 55,3 & 44,7 \\
Urbano & 83,3 & 16,7 \\
Solo exposto & 27,3 & 72,7 \\
Corpos d' água & 100,0 & 0 \\
\hline Exatidão global (Usuário) & $\mathbf{6 2 , 0 2}$ & $\mathbf{3 7 , 9 8}$ \\
\hline
\end{tabular}

Tabela 07: Classificação do Usuário para o mapeamento do INPE. Fonte: Elaborado pelo autor.

Na Tabela 06, referente à "Classificação do Produtor" observa-se que a classe "corpos d'água" obteve maior veracidade em seus dados com valores máximos de concordância.

A classe lavoura obteve $86,7 \%$ de veracidade de seus dados. Vale frisar que nesta classe, houve a junção das classes referente à agricultura temporária e permanente.

A classe Caatinga degradada obteve 52,6\% de seus pontos classificados corretamente, tendo 47,4 \% de erro de comissão. Isso se deve ao fato de alguns pontos terem sido confundidos com a classe Caatinga preservada, podendo ser explicado pela proximidade dos intervalos de reflectância das classes de cobertura da terra definidas no mapeamento realizado pelo INPE.

A classe solo exposto teve uma concordância de $42,9 \%$, tendo parte dos pontos confudidos e classficados como Caatinga degradada e lavoura, comprometendo assim a acurácia dos mesmos.

A classe urbano obteve apenas 38,5\% de acurácia em seus dados, explicado pelo fato de alguns pontos terem sido classificados com solo exposto. Essa "confusão" gerada também pode 
explicar o baixo valor de concordância para a categoria de Caatinga preservada, que foi de $21,7 \%$, onde a maioria dos pontos foram confundidos com Caatinga degradada.

Contudo, o índice de Exatidão Global para a classificação do produtor foi de $\mathbf{5 7 , 0 6 \%}$ considerado como "muito boa", conforme a classificação de Landis e Kock (1977).

$\mathrm{Na}$ “Classificação do Usuário" (Ver tabela 07) a classe corpos d'água também obteve 100\% de acurácia.

A classe urbano teve $83,3 \%$ de seus pontos classificados corretamente, $16,7 \%$ foram confudidos e classificados com lavoura compromentendo a classificação.

A classe Caatinga degradada obteve $64,5 \%$ de acertos em seus pontos, quase $1 / 4$ das amostras tiveram erros de comissão confudidos com Caatinga preservada.

Com 55,3\% de acertos, a classe lavoura obteve um erro de comissão de 44,7\%, podendo ser explicado em função da mesma ter alguns de seus pontos classificados como Caatinga preservada.

A classe referente à Caatinga preservada teve quase a metade de seus pontos classificados como Caatinga degradada, a mesma teve um acerto de $41,7 \%$, enquanto que solo exposto obteve $27,3 \%$ de acertos, tendo $72,7 \%$ de seus pontos confundidos principalmente com a classe de urbano.

Contudo, a "Classificação do usuário" foi um pouco superior a "Classificação do produtor" para o mapeamento de cobertura da terra realizado pelo INPE, com um índice de Exatidão Global de 62,02 \%, enquadrando-se na tabela de Landis e Kock (1977) como "muito boa".

Em suma, a classificação do INPE obteve um índice de Exatidão Global de 55,20\%, sendo considerada como "Boa" segundo Landis \& Kock, (1977). Como o índice de exatidão global trabalha apenas com os resultados classificados como "certo" dentro da matriz de confusão, aplicou-se também o índice Kappa, que foi de 43,21\%, enquadrando-se como "Boa" segundo Landis \& Kock (1977).

Vale salientar que o mapeamento realizado pelo INPE, obteve seis classes de cobertura da terra para o município, dessa forma, algumas das classes que foram observadas separadamente em campo, como por exemplo; agricultura temporária e permanente, tiveram que ser agrupadas no mapeamento realizado pelo INPE, fato esse que pode ter influenciado nos valores na acurácia do mapeamento realizado pelo mesmo. Como também o período no qual o INPE realizou o trabalho (2008), que foi um ano de La Niña, podendo haver/gerar confusão entre as categorias de vegetação lavoura, solo exposto e corpos d' água, já que o periodo que foram realizadas as visitas em campo para a obtenção dos pontos de controle foi no periodo de El Niño, sendo setembro, naturalmente, o mês mais seco no Município. 


\section{CONSIDERAÇÕES FINAIS}

$\mathrm{Na}$ avaliação da precisão do mapeamento de cobertura da terra realizado pelo INPE a partir de uma matriz de confusão, os índices de exatidão global e o índice Kappa mostraram-se como ótimas opções no que diz respeito à análise da vericidade desses dados.

Vale frisar que, devido o Índice de Exatidão Global levar em conta na matriz de confusão apenas os valores classificados corretamente, o mesmo obteve resultados superiores ao Índice Kappa. Como também o período no qual o INPE realizou o trabalho (2008) que foi um ano de $L a$ Niña, e o periodo que foram realizadas as visitas em campo para a obtenção dos pontos de controle foi no periodo de El Niño sendo setembro, naturalmente, o mês mais seco no Município podendo ter então gerado uma confusão entre algumas categorias.

Dessa forma, tanto o índice de exatidão global como o índice Kappa mostraram-se satisfatórios como ferramentas para a avaliação da acurácia das classificações obtidas para os mapeamentos de cobertura da terra realizados para o município de Martins - RN.

\section{REFERÊNCIAS}

AB'SABER, A. N. Sertões e sertanejos: uma geografia humana sofrida. Estudos Avançados 13 (36), 1999.

ALVARES, C. A; STAPE, J. L; SENTELHAS, P. C; GONÇALVES, J. L. M; SPAROVEK, G. Köppen's climate classification map for Brazil. Meteorologische Zeitschrift, Fast Track. 2013.

ANDRADE-LIMA, D. The Caatinga dominium. Revista Brasileira de Botânica, São Paulo. v.4, p. 149-153,1981.

CONGALTON, R. G. A review of assessing the accuracy of classifications of remotely sensed data. Remote Sensing of Environment, v.49, n.12, p.1671-1678, 1991.

CPRM - Serviço Geológico do Brasil. Projeto cadastro de fontes de abastecimento por água subterrânea. Diagnóstico do município de Martins, estado do Rio Grande do Norte. CPRM/PRODEEM, Recife /PE, 2005.

Departamento de Ciencias Atmosféricas da Universidade Federal de Campina Grande - UFCG. Disponível em:<http://www.dca.ufcg.edu.br/clima/dadosrn.htm>. Acesso em: 02 de maio de 2015. 
Disponível em <http://www.sat.cnpm.embrapa.br>. Acesso em 12 de janeiro de 2016.

Disponível em <http://www.geopro.crn2.inpe.br/martins_rn.htm> Acesso em 10 de outubro de 2014.

Disponível em <http://www.hexagongeospatial.com/products/producer-suite/erdas-imagine> Acesso em 12 de janeiro de 2016.

Disponível em <http://www.trackmaker.com/index.php?lang=port>

FOODY, G. M. Status of land cover classification accuracy assessment. Remote Sensing of Environment. v80. p 185 - 201, 2002.

INSTITUTO BRASILEIRO DE GEOGRAFIA E ESTATÍSTICA - IBGE.

Perfil do Município de Martins/RN. Disponível em: $<$ http://www.cidades.ibge.gov.br/xtras/perfil.php?lang=\&codmun=240740>: Acesso em 02 de maio de 2015.

. Manual técnico da vegetação brasileira. 2 ed. Manuais Técnicos em Geociências, n. 1, Rio de Janeiro: Ministério do Planejamento, Orçamento e Gestão/IBGE/Diretoria de Geociências/Coordenação de Recursos Naturais e Estudos Ambientais. Rio de Janeiro, 2012.

. Manual Técnico de Uso da Terra. Editora: IBGE, 2. ed, Rio de Janeiro/RJ, 2006.

. Manual técnico de pedologia, Coordenação de Recursos Naturais e Estudos Ambientais. 3. ed. - Rio de Janeiro: IBGE, 2015.

JACOMINI, P. K. et al. Levantamento exploratório-reconhecimento de solos do estado do Rio Grande do Norte. Recife: SUDENE/Divisão de Pesquisa Pedológica, v.1, 531 p. (sér. Boletim Técnico, n. 21; sér. Pedologia, n. 9). Recife/PE, 1971.

LANDIS, J. R; KOCH, G. G. The measurement of observer agreement for categorical data. Biometrics, v. 33, n. 1, p. 159-174. 1977.

PONZONI, F. J; ALMEIDA, E. S. A estimativa do parâmetro kappa (k) da análise multivariada discreta no contexto de um SIG. Anais... Simpósio Brasileiro de Sensoriamento Remoto. Salvador BA, 1996.

PONZONI, F. J; SHIMABUKURO, Y. E. Sensoriamento Remoto no Estudo da Vegetação. Instituto Nacional de Pesquisas Espaciais - INPE. São José dos Campos/SP, 2010. 
PRADO, D. As caatingas da América do Sul. In: LEAL, I. R; TABARELLI, M; SILVA, J. M. C. (eds.). Ecologia e conservação da Caatinga. Editora Universitária, Universidade Federal de Pernambuco, Recife, Brasil. pp. 3-73. 2003.

REIS, A. C. Clima da Caatinga. Anais da Academia Brasileira de Ciências. 48: 325-335. 1976.

SALGADO, O, A; JORDY-FILHO, S; GONÇALVES, L. M. C. Vegetação: As regiões fitoecológicas, sua natureza e seus recursos econômicos; Estudo Fitogeográfico. In: BRASIL, PROJETO RADAMBRASIL. Folhas SB. 24/25 Jaguaribe/Natal, Rio de Janeiro - RJ, 1981.

SAMPAIO, E. V. S. B. Overview of Brazilian Caatinga. In: Bullock, S.H; Money, H.A; Medina, E. (eds.). Seasonally dry tropical forests. New York: Cambridge University Press, p. 35-63.1995.

VELlOSO, A. L; SAMPAIO, E. V. S. B; PAREYN, F. G. C. Ecorregiões Propostas para o Bioma Caatinga. Associação Plantas do Nordeste; Instituto de Conservação Ambiental The Nature Conservancy do Brasil, Recife/PE, 2002.

WALTER, H. Vegetação e Zonas Climáticas: Tratado de Ecologia Global. Tradução de Anna Terzi Giova, Hildegard T. Buckup. São Paulo: EPU, 1986.

\section{AGRADECIMENTOS}

A Coordenação de Aperfeiçoamento de Pessoal de Ensino Superior (CAPES) pela concessão da bolsa de pesquisa.

Recebido em: 15/08/2018

Aceite para publicação em: 05/11/2018 